\title{
Nucleotide Sequence Comparison of the Adh Gene in Three Drosophilids
}

\author{
Vivian H. Cohn, Margaret A. Thompson ${ }^{1}$, and Gordon P. Moore \\ Division of Biological Sciences, University of Michigan, Ann Arbor, Michigan 48109, USA
}

Summary. The alcohol dehydrogenase (Adh) gene has been isolated from Drosophila simulans and $D$. mauritiana by screening $\lambda$ clone libraries of each with a previously cloned Adh gene from $D$. melanogaster. The isolated $\lambda$ clones were subcloned and partially sequenced to determine the relatedness of these species and to examine details of evolutionary change in the structure of the Adh gene. We report the sequence of the first 704 nucleotides of each gene as well as 127 bases in the $5^{\prime}$ untranslated region. When these sequences are compared, $D$. melanogaster differs from $D$. simulans and $D$. mauritiana by $2.8 \%$ and $3.1 \%$, respectively. $D$. simulans and $D$. mauritiana differ by only $1.8 \%$, implying that they are more closely related to each other than either is to $D$. melanogaster. This is consistent with phylogenetic relationships established by a variety of genetic, biochemical, and morphological means and illustrates that DNA sequencing of a single gene may be used to assess the evolutionary relationships of species.

Key words: Alcohol dehydrogenase - DNA sequence - Drosophilids

\section{Introduction}

The alcohol dehydrogenase (Adh) gene of $D$. melanogaster has been intensively studied and has many interesting features. Alcohol dehydrogenase protein (ADH) is abundant and has been purified and characterized (Sofer and Ursprung 1968); its complete amino acid sequence has been determined (Thatcher

\footnotetext{
Offprint requests to: G.P. Moore

${ }^{1}$ Present address: The Biological Laboratories, Harvard University, Cambridge, Massachusetts 02138, USA
}

1980). In addition, the gene has been cloned and the nucleotide sequence of introns, exons, and flanking DNA determined (Benyajati et al. 1980, 1981; Goldberg 1980; C. Benyajati unpublished). The Adh gene has been genetically and cytologically mapped with considerable accuracy owing to the availability of both overproducing and null mutants (e.g., O'Donnell et al. 1978; Woodruff and Ashburner 1979). Expression of the Adh gene is developmentally regulated and tissue specific (e.g., Ursprung et al. 1970). It has recently been shown that this expression is controlled by two promoters, one of which is active in early development and the other of which functions at later stages (Benyajati et al. 1983).

Our laboratory has been interested in the evoIution of the Adh gene. Drosophila ADH is quite different from those of mammalian liver and yeast. The subunit molecular weight is less $(25,000$ daltons in Drosophila, 39,800 daltons in liver, and 35,300 daltons in yeast) and Drosophila ADH does not require $\mathrm{Zn}^{2+}$ for enzymatic activity, as does $\mathrm{ADH}$ of other species (Benyajati et al. 1980). Moreover, the amino acid sequence of Drosophila ADH shows little homology to that of $\mathrm{ADH}$ from liver or yeast. Nevertheless, it has been possible to align the amino acid sequence of the three ADH proteins using computer predictions of secondary structure (Benyajati et al. 1980). Based on this analysis, the positions of two introns in the $D$. melanogaster Adh gene (after amino acids 33 and 168 , numbering ATG as codon 1) were examined relative to structural "domains" of the protein. Interestingly, one intron appears to fall between two domains, as predicted by the geneshuffing hypothesis of Gilbert (1978), while the other does not. It seems worthwhile to examine Adh in other drosophilids to see whether the position of one or both of these introns has been conserved during evolution.

We have previously used a cloned fragment of 
the $D$. melanogaster Adh gene as a probe to quantitate divergence of various species of Drosophila by DNA hybridization and thermal elution from hydroxyapatite (Zwiebel et al. 1982). In the present article, we extend these studies by reporting the DNA sequences of the first 704 nucleotides of the Adh gene from $D$. simulans and $D$. mauritiana, as well as of 127 nucleotides in the 5 ' untranslated region.

\section{Materials and Methods}

Isolation of Adh-Containing $\lambda$ Clones. Clone libraries of $D$. simulans and $D$. mauritiana were kindly provided by $\mathrm{Dr}$. M. Meselson. These were screened by modification of the procedures of Benton and Davis (1977) as described previously (Zwiebel et al. 1982). Libraries were screened with a $D$. melanogaster Adhcontaining clone kindly provided by $\mathrm{D}$. Goldberg. Isolated $\lambda$ clones were propagated, and DNA was extracted as described by Blattner et al. (1977). Maps of restriction enzyme cleavage sites were constructed by digestion, electrophoresis, and Southern transfer as described previously (Zwiebel et al. 1982).

Subcloning. The isolated $\lambda$ clones were digested with Eco RI. DNA isolated from the plasmid pBR 325 (chosen because it contains a selectable marker interrupted by an Eco RI site) was digested with Eco RI and treated with calf intestinal alkaline phosphatase (Boehringer Mannheim). The enzyme was suspended in $10 \mathrm{mM}$ Tris- $\mathrm{HCl}$, pH $8.0,50 \mathrm{mM} \mathrm{KCl}, 1 \mathrm{mM} \mathrm{MgCl}_{2}, 0.1$ $\mathrm{mM} \mathrm{ZnCl}, 50 \%$ glycerol; added to Eco RI-digested vector DNA in $10 \mathrm{mM}$ Tris- $\mathrm{HCl}, \mathrm{pH} 8.0$; and incubated for $1 \mathrm{~h}$ at $65^{\circ} \mathrm{C}$. Phosphatased vector DNA was extracted twice with Tris-saturated phenol and once with Sevag (24:1, chloroform/isoamyl alcohol). Vector and $\lambda$ clone DNAs were combined and coprecipitated. The pellet was resuspended in $5 \mathrm{mM}$ Tris- $\mathrm{HCl}, \mathrm{pH}$ 7.6; and ligated in $0.6 \mathrm{mg} / \mathrm{ml} \mathrm{ATP}, 66 \mathrm{mM}$ Tris- $\mathrm{HCl}$, pH 7.6, $6.6 \mathrm{mM} \mathrm{MgCl}_{2}, 10 \mathrm{mM}$ dithiothreitol, and 4.5 units of T4 ligase (BRL) for $25 \mathrm{~h}$ at $15^{\circ} \mathrm{C}$. Ligated samples were used to transform $E$. coli strain $\mathrm{HB} 101$ and cells were plated on L-broth agar plates containing $25 \mu \mathrm{g} / \mathrm{ml}$ ampicillin. Colonies were replica plated onto chloramphenicol-containing plates, and those which failed to grow were cultured and screened by Southern Transfer for the presence of Adh-containing fragments. Positive subclones were grown and their DNA was isolated; maps of restriction enzyme cleavage sites were constructed as described above.

DNA Sequencing. DNA sequencing was performed by the chemical cleavage method of Maxam and Gilbert (1977). Three types of ${ }^{32} \mathrm{P}$ end-labeling were employed: (a) labeling at $3^{\prime}$ recessed ends with the large fragment of polymerase I (BRL); (b) labelling at 5 ' protruding ends with polynucleotide kinase ( $\mathrm{P}-\mathrm{L}$ Labs); and (c) labeling at $3^{\prime}$ protruding ends with terminal deoxynucleotide transferase (NEN) and cordycepin 5 -triphosphate $\left(\alpha-{ }^{32} \mathrm{P}\right)$. Chemical reactions, electrophoresis, and gel elutions were performed using standard methods. Confirmation of sequence was obtained by sequencing both strands when possible, by overlapping fragments (see Fig. 1), and by repeated labelings.

\section{Results}

The Adh gene was isolated from genomic $\lambda$ clone libraries of $D$. mauritiana and $D$. simulans by Benton and Davis's (1977) plaque hybridization method using a cloned $D$. melanogaster Adh gene as the
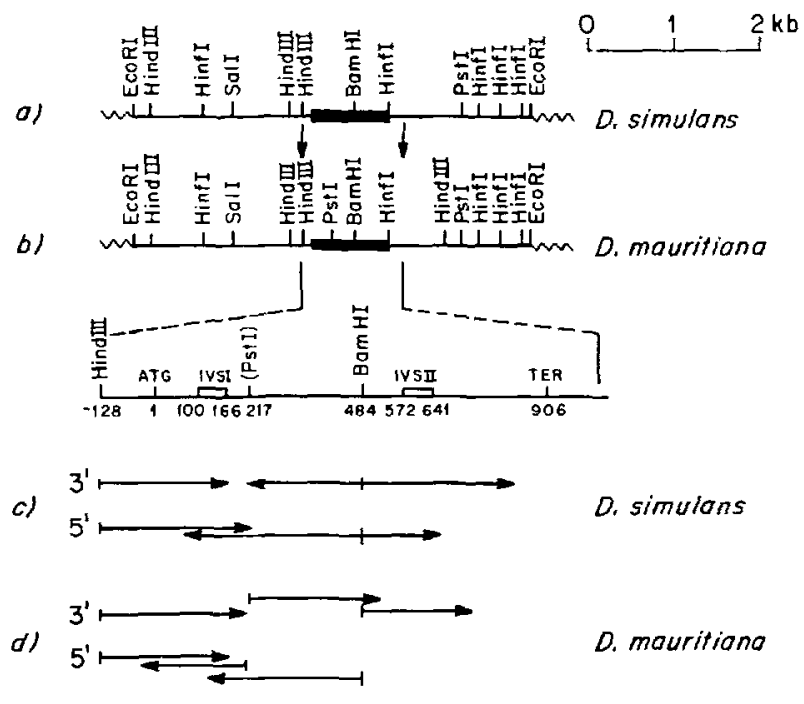

D. simulons

D. mauritiana

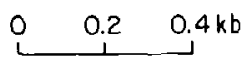

Fig. 1. Restriction enzyme cleavage sites in Adh-containing clones from (a) $D$. simulans and (b) D. mauritiana. The Adh gene itself is indicated by a thickened line; the wavy line indicates the vector $\mathrm{pBR}$ 325. Strategies used in DNA sequencing of the Adh gene of D. simulans and D. mauritiana are shown in (c) and (d). The Pst $I$ site in parentheses in the schematic occurs only in $D$. mauritiana. IVSI, Intron 1; IVSII, intron 2; TER, termination of translation

probe. Restriction maps were constructed using standard techniques. The $\lambda$ clones were digested with Eco RI and the resultant fragments subcloned into the plasmid pBR 325. The subclones were extensively mapped for restriction sites, and then regions containing the Adh gene were sequenced using the procedure of Maxam and Gilbert (1977). The sequencing strategy, which employed overlapping fragments and both 3 ' and 5' labeling, is outlined in Fig. 1. Confirmation of sequence was obtained by sequencing both strands whenever possible, and by repeated labelings. The sequences of $831 \mathrm{nu}$ cleotides within and $5^{\prime}$ to the Adh genes of $D$. simulans and $D$. mauritiana were determined and are shown in Fig. 2. The sequences include DNA 5 ' to the gene, the first two exons, and both introns, as well as a portion of exon 3 . The $D$. melanogaster Adh sequence determined by $C$. Benyajati (1981 and unpublished data) is shown for comparison.

The determined sequence starts 127 nucleotides upstream from the ATG start site of translation. Two deletions/insertions of a single base occur in the $5^{\prime}$ flanking region of the gene. 102 nucleotides upstream from the ATG codon is an AT-rich region (TATAAATA), identical in all three species, that may correspond to the TATA or Goldberg-Hogness box commonly found 5 ' to eucaryotic genes (Goldberg 1979). The distance between this region and the ATG site is approximately that expected based 
2. simuians AAGCTTCTGC ${ }^{-120}$ GTACGGATACTTCCTATAAATACGGGG CCGACACGAA 0. mauritiano AAGCTTCTGC GTACGGATACT TCCTATAAAT ACGGGGCCGACACGAA 0. melanogoster AAGCT TCTGCUG T AC G GATUCT TCCTATAAATAC GGG GCC GACAC GAA - 60

CTGG AAACC AACAACTAACGGAGCCCTCT TCCCATTGAAACAGATCGAA CTG GAAACCAACAACTAACG GAGCCCTCTTCCCATTG AAACAGATCGAA CTGGAAACCAACAAC TAACGGAG CCCTCTTC CLAATTG AAACAGATCGAA

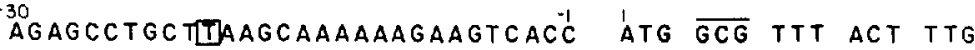
AGAGCCTGCTAAAGCAAAAAAGAAGTCACC ATG GCG TTT ACT TTG AGAGCCTGCTAAAGCAAAAAAGAAGTCACC ATG TICG TTT ACT TTG

ACC AAC AAG AAC GTG ATT TTC GTT GCC GGT CTG GGA GGC ACC AAC AAG AAC GTG ATT TTC GTT GCC GGC CTTG GGA GGC ACC AAC AAG AAC GTG ATT TTC GTT GCC GGT CTG GGA GGC ATC GGT CITG GAC ACC AGC AAG GAG CTG $\overline{C T C}$ AAG CGC GAC ATT GGT CTG GAC ACC AGC AAG GAG CTG [GTC AAG CGC GAC ATT GGT CTG GAC ACC AGC AAG GAG CTG CTC AAG CGC GATU CTG AAG $[100$ GTAATATGCGATGCCCACAGGTTCCATG GAG GGGOATIJGA CTG AAG GTAACTATGCGATGCCCACAGGTTCCATGGAGGG ATGGA CTG AAG [GTAACTATGCGATGCCCACAGGCT CCATGCAGCE ATGGA GGTTAATCTCGTGTATTCAATCCTAG] ${ }^{167}$ AAC CTG GTA ATC CTC GAC GGTTAATCTCATGTATT DTATCCTAG AAC CTG GTG ATC CTC GAC GGTTAATCTCGTGTATTCAATCCTAG AAC CTG GTG ATC CTC GAC CGC ATT GAG AAC ${ }^{197}$ CCG GCT GCC ATT GCC GAG CTG $\overline{A A G}$ CGC ATT GAG AAC CCIT GCT GCC ATT GCC GAG CTG C]AG CGC ATT GAG AAC CCG GCT GCC ATT GCC GAG CTG AAG $\overline{G T A}$ ATC ${ }^{227}$ AAT CCA AAG GTG ACC GTC ACC TTC TAC CCC GCA ATC AAT CCA AAG GTG ACC GTC ACC TTC TAC CCC GCA ATC AAT CCA AAG GTG ACC GTC ACC TTC TAC CCC

${ }^{257}$ IAT GAT GTG ACC GTG CCC ATT GCC GAG ACC $\stackrel{287}{A C C}$ AAG TAT GAT GTG ACC GTG CCC ATT GCC GAG ACC ACC AAG TAT GAT GTG ACC GTG CCC ATT GCC GAG ACC ACC AAG CTG CTG AAG ACC ATC TTC GCC $\overline{A A G}$ CITG AAG ACC GTC CTG CTG AAG ACC ATC TTC GCC AAG CTG AAG ACC GTC CTG CTG AAG ACC ATC TTC GCC GAG CTG AAG ACC GTC GAT GTC CTG ATC AAC GGA 347 GCT GGT ATC CTG GAC GAT GAT GTC CTG ATC AAC GGA GCT GGT ATC CTG GAC GAT GAT GTC CTG ATC AAC GGA GCT GGT ATC CTG GAC GAT CAC CAG ATC GAG ${ }^{377}$ CGC ACC ATT GCC GTC AAC TAC ACT CAC CAG ATC GAG CGC ACC ATT GCC GTC AAC TAC ACT CAC CAG ATC GAG CGC ACC ATT GCC GTC AAC TAC ACT GGC CTG ${ }^{407}$ GT AAC ACC ACG ACG GCC ATT CTG GAC TTC GGC CTG GTC AAC ACC ACG ACG GCC ATT CTG GAC TTC GGC CTG GTC AAC ACC ACG ACG GCC ATT CTG GAC TTC ${ }^{437}$ TGG GAC AAG CGC AAG GGT GGT CCC GGT GGT ATTC ATC TGG GAC AAG CGC AAG GGT GGT CCC GGT GGT ATC ATC TGG GAC AAG CGC AAG GGO GGT CCC GGT GGT ATC ATC

TGC AAC ATT GGA TCC GTC ACT GGT ${ }^{497} T C$ AAT GCC ATC TGC AAC ATT GGA TCC GTC ACT GGT TTC AAT GCC ATC TGC AAC ATT GGA TCC GTC ACT GGD TTC AAT GCC ATC TAC CAG GTG CCC GTC TAC ${ }^{527}$ TC GGC AAC AAG GCC GCN TAC CAG GTG CCC GTC TAC TCC GGC

TAC CAG GTG CCC GTC TAC TCC GGC ACC AAG GCC GCC GTG GTC AAC TTC ACC AGC TCC CTG GCG [572 5 GAGTTCATC GTG GTC AAC TTC ACC AGC TCC CTG GCG GTAAGTTCATC GTG GTC AAC TTC ACC AGC TCC CTG GCG [GTAAGTTGATC GAAGGAAACG CAAAGTTTTCAAAAAATTAA AAAAC TAAT TTGT TTTAT GAAGGAAACGCAAAGTTT AAAAAGACAA AAAACTAATTTGTTTTAT AAAGgAAAC GCAAAG TT TUCAAGAAAAAACAAAACT AATTT GबT TT AT A32 $A C A C C T T T A G$ G42

AACACCTTTAG GA2 $\triangle A A$ CTG GCC CCC ATT ACC GGC GTG ACC AACACCTTTAG AAA CTG GCC CCC ATT ACC GGC GTG ACC AACACCTTTAG AAA CTG GCC CCC ATT ACC GGC GTG ACC GCT N NAC ACC GTG AAC CCC GGC ATC ACC CGC ACC ${ }^{702}$ GCT NAC ACC GTG AAC CCC GGC ATC ACC CGC ACC ACC GCT TAC ACC GTG AAC CCC GGC ATC ACC CGC ACC ACC
Fig. 2. DNA sequences within and $S^{\prime}$ to the Adh genes of $D$. simulans and $D$. mauritiana. The previously determined sequence of $D$. melanogaster Adh (Benyajati et al, 1981 and unpublished) is shown for comparison. The position of introns is indicated by brackets. Nucleotide substitutions are boxed and deletions/insertions are indicated by circles. Codons that undergo nucleotide change leading to amino acid replacement are overlined. The gap at nucleotide 533 indicates a region of twelve nucleotides that have not been determined in $D$. mauritiana. Sequence ambiguities (positions 45,544 , and 672 ) have not been scored as nucleotide changes in Tables 1 and 2. Position 1 is the ATG start site of translation on the estimated length of the $5^{\prime}$ leader sequence of Adh mRNA of adult fiies (Benyajati et al. 1980). The eight nucleotide AT-rich region is followed im- mediately by eight nucleotides of GC. Intron 1 occurs at nucleotide 100 (after amino acid 33) and intron 2 at nucleotide 572 (after amino acid 168) in 
Table 1. Percentage of DNA sequence divergence in and around the Adh gene of three drosophilids ${ }^{2}$

\begin{tabular}{|c|c|c|c|c|c|c|c|c|c|}
\hline \multirow[b]{2}{*}{ Species } & \multirow{2}{*}{$\begin{array}{l}5^{\prime} \\
\text { flanking } \\
\text { DNA }\end{array}$} & \multicolumn{3}{|c|}{ Exons } & \multicolumn{2}{|c|}{ Introns } & \multirow{2}{*}{$\begin{array}{l}\text { All } \\
\text { exons }\end{array}$} & \multirow{2}{*}{$\begin{array}{l}\text { All } \\
\text { introns }\end{array}$} & \multirow{2}{*}{$\begin{array}{l}\text { En- } \\
\text { tire } \\
\text { se- } \\
\text { quence }\end{array}$} \\
\hline & & 1 & 2 & $3^{b}$ & 1 & 2 & & & \\
\hline D. simulans/D. melanogaster & 3.1 & 3.0 & 1.2 & 0 & 7.5 & 8.6 & 1.4 & 8.0 & 2.8 \\
\hline D. simulans/D. mauritiana & 0.8 & 2.0 & 1.0 & 0 & 6.0 & 5.7 & 1.1 & 5.8 & 1.8 \\
\hline D. mauritiana/D. melanogaster & 2.4 & 3.0 & 1.3 & 0 & 7.5 & 12.9 & 1.4 & 10.2 & 3.1 \\
\hline
\end{tabular}

- Deletions/insertions are scored as single events

b Calculated based on the first 63 nucleotides of exon 3

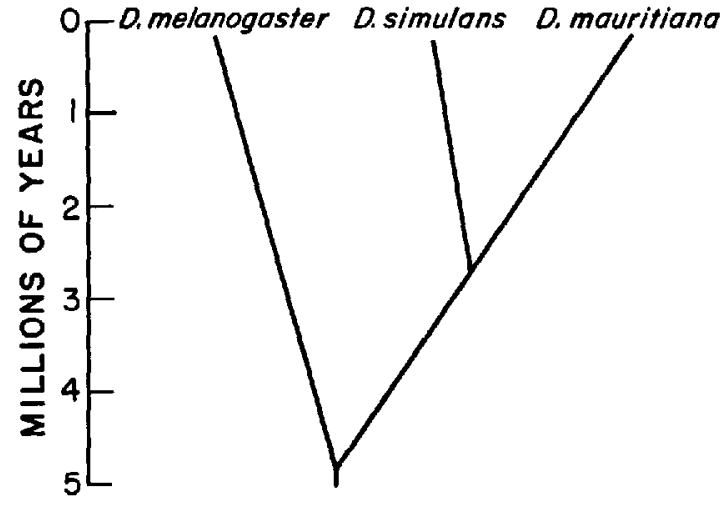

Fig. 3. Evolutionary relationship among three drosophilids as deduced from nucleotide sequence comparison of the Adh genes. The indicated divergence times are maximal estimates

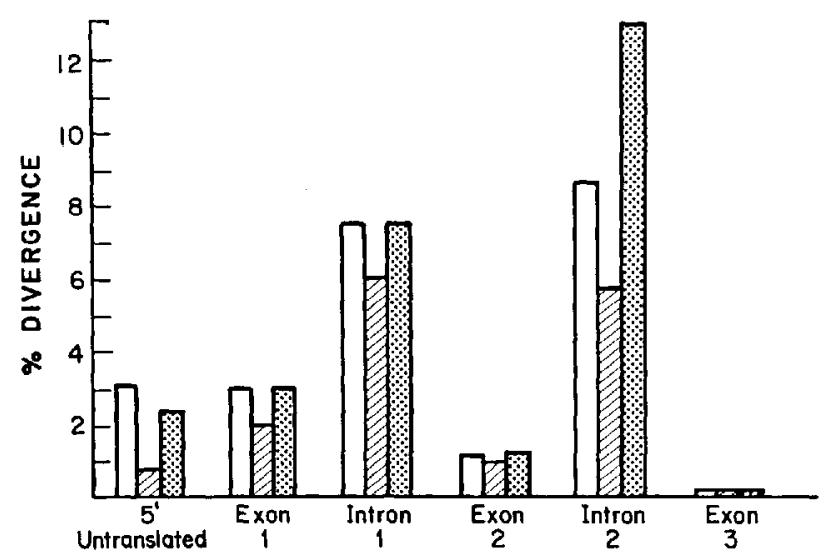

Fig. 4. Distribution of base changes in the Adh genes of three drosophilids. The open bar indicates $D$. melanogaster compared with $D$. simulans; the hatched bar indicates $D$. mauritianalD. simulans; and the stippled bar indicates $D$. melanogaster/D. mauritiana. The data are taken from Fig. 2 and Table 1 . There are no nucleotide changes within the 63 sequenced nucleotides of exon 3

all three species. Both introns conform to the consensus splicing rules suggested by Breathnach and Chambon (1981). The lengths of the introns vary slightly among the three species due to short insertions/deletions, which are common in eucaryotic introns (Moore 1983). The introns are more AT rich than is the structural gene; this is particularly true for intron 2, which is approximately $74 \% \mathrm{AT}$.

Over the entire length of the determined sequence, $D$. simulans and $D$. mauritiana are clearly more similar to each other than either is to D. melanogaster. As shown in Table $1, D$. simulans and D. mauritiana differ from each other in $1.8 \%$ of the bases, whereas they differ from $D$. melanogaster by $2.8 \%$ and $3.1 \%$ of the bases, respectively. This sequence comparison suggests the evolutionary relationship among the three species outlined in Fig. 3, which indicates that $D$. simulans and $D$. mauritiana diverged from each other after their joint divergence from $D$. melanogaster. This phylogeny agrees with others constructed on the basis of both molecular and nonmolecular characteristics (see Discussion).

DNA sequence divergences can be compared in 5 ' flanking DNA, each exon, and each intron (see Table 1 and Fig. 4). The introns diverge at least five times more rapidly than do the coding regions of the gene. Intron 2 may diverge slightly more rapidly than intron 1 , and exon 1 may diverge slightly more rapidly than exon 2 , but the differences are not statistically significant. Although there is little divergence in exon 3, the sequence has not been determined completely; thus a full comparison cannot yet be made. The $5^{\prime}$ flanking DNA diverges significantly less rapidly than does DNA in introns, which may be the result of evolutionary constraints on sequence divergence in this region.

Sequence divergence can also be examined with regard to placement of individual nucleotide changes, as shown in Table 2. Nucleotide changes in the third positions of codons are somewhat more frequent than changes in position 1 . Changes in position 1 are four times as common as those in position 2 . Nucleotide changes that lead to amino acid substitutions are less frequent than silent changes, but this effect is not as strong as might have been expected. When the three sequences are aligned, there are 12 silent and 10 replacement changes. The ratio of silent to replacement changes increases significantly, however, when the data are corrected using the method of Perler et al. (1980). Using this method to correct for the potential number of silent and 
Table 2. Number of nucleotide differences among the Adh genes of three drosophilids

\begin{tabular}{|c|c|c|c|c|c|c|c|c|}
\hline \multirow[b]{2}{*}{ Species compared } & \multicolumn{3}{|c|}{$\begin{array}{l}\text { Change in } \\
\text { codon position }\end{array}$} & \multirow{2}{*}{$\begin{array}{l}\text { Silent } \\
\text { changes }^{*}\end{array}$} & \multirow{2}{*}{$\begin{array}{l}\text { Amino } \\
\text { acid } \\
\text { replace- } \\
\text { ment } \\
\text { changes }\end{array}$} & \multirow{2}{*}{$\begin{array}{l}\text { Inser- } \\
\text { tions } \\
\text { or } \\
\text { deletions }^{b}\end{array}$} & \multirow{2}{*}{$\begin{array}{l}\text { Transi- } \\
\text { tions }^{b}\end{array}$} & \multirow{2}{*}{$\begin{array}{l}\text { Trans- } \\
\text { ver- } \\
\text { sions }^{b}\end{array}$} \\
\hline & 1 & 2 & 3 & & & & & \\
\hline D. simulans/D. melanogaster & 2 & 1 & 5 & 5 & 3 & 4 & 8 & 11 \\
\hline D. simulans/D. mauritiana & 2 & 1 & 3 & 3 & 3 & 2 & 7 & 6 \\
\hline D. mauritiana/D. melanogaster & 4 & 0 & 4 & 4 & 4 & 4 & 8 & 13 \\
\hline
\end{tabular}

a Based on comparison of coding DNA only; data from Fig. 2

'Based on comparison of introns, exons, and 5' flanking DNA; data from Fig. 2

replacement sites in each codon, the ratio of silent to replacement changes increases to 5.7 for $D$. simulans/D. melanogaster, 2.7 for $D$. simulans/ $D$. mauritiana, and 3.4 for D. melanogaster/D. mauritiana. There does not appear to be any special bias toward transitions rather than transversions, such as has been reported for mitochondrial DNAs (e.g., Brown et al. 1982).

Insertion or deletion events in noncoding DNA have occurred often since the species diverged. It is difficult to distinguish conclusively between insertions and deletions. However, assuming that the phylogeny of Fig. 3 is correct (see Discussion), those cases in which $D$. melanogaster shares a nucleotide(s) with one, but not both, of the other two species are probably the result of an event that took place in the species with the unique base(s). For example, in the first intron, at nucleotide 134, there are two nucleotides that occur in $D$. simulans but not in $D$. melanogaster or D. mauritiana. It seems most likely that an insertion has occurred in $D$. simulans rather than two independent deletions at the same location in $D$. melanogaster and $D$. mauritiana. In coding DNA there is no evidence of clustering of base changes, which would indicate "hotspots" of mutational events; there is no single position at which each species has a different base. In noncoding regions, base changes and insertions/deletions do appear to be clustered. The ratio of insertions/deletions to base changes in noncoding DNA is 0.32 ; this is similar to the value of 0.28 reported by Cann and Wilson (1983) for many noncoding DNAs.

\section{Discussion}

The DNA sequence of the Adh gene has been compared among three species of Drosophila. Although many genes have been compared in related eucaryotes, very few have been compared among drosophilids. The organization of the genome as a whole, as well as of individual genes, in $D$. melanogaster is different from that of most other eucaryotes in important features such as genome size, interspersion of repeats, intron size and number, etc. (see Spradling and Rubin 1981 for a review). To understand the unusual evolutionary history of drosophilids, detailed interspecies comparisons at the DNA level will have to be made.

Adh is an excellent gene with which to study evolution in drosophilids at the DNA level. It is a small gene and occurs in all species examined. Moreover, an enormous amount of information on it exists with which to put evolutionary comparisons into context. Adh has been analyzed extensively with respect to protein chemistry, genetics, cytology, development, geographical distribution of alleles, and, more recently, the structure of the gene itself. Interspecies comparison may suggest what features of gene structure are critical (thus evolutionarily conserved) and may reveal the nature and rate of evolutionary change.

In this initial study, we have chosen to investigate three species known by several criteria (see below) to be closely related. The advantage in comparing closely related species is that observed differences probably reflect primary events unlikely to be obscured by secondary mutations. Clearly it will also be important to extend this comparison to more distantly related species. The kinds of evolutionary changes observed in the Drosophila Adh gene seem analogous to those of gene evolution in other species. For example, the introns diverge more rapidly than the exons; intron position is conserved, but intron length varies as the result of short insertions or deletions; introns are more AT rich than the rest of the gene; and intron/exon borders conform to the consensus sequences seen in other species. Intron position is conserved even in the case of an intron that does not fall between obvious domains of the protein. Conservation of an intron that interrupts a domain may be interpreted as an exception to Gilbert's (1978) suggestion of intron shuffling; however, 
there may be domains of the Adh protein of which we are unaware. Intron/exon junctions have been shown to occur outside the hydrophobic core, on the surface of the corresponding protein (Craik et al. 1982). Gō (1981) has proposed that introns fall between subdomains or "modules." The first intron of the Adh gene may separate such modules. Certainly analysis of more distantly related species of Drosophila will be important in this context.

It is of particular interest to compare the data presented here with those of Kreitman (1983), who reported the sequences of 11 cloned Adh genes from five natural populations of $D$. melanogaster. Kreitman identified 14 polymorphic sites in coding DNA, only one of which leads to an amino acid replacement. From the low number of amino acid polymorphisms he concluded that virtually all the amino acids of the protein are under selection pressure. The interspecies comparisons reported here show a significantly greater number of amino acid replacements, which suggests that these sibling species may be under somewhat different selective constraints. Ultimately, detailed comparison of interspecies and intraspecies divergence may enhance our understanding of the relationship between speciation and polymorphism.

In addition to demonstrating nucleotide polymorphisms, Kreitman's analysis revealed differences in length (i.e., deletions/insertions) among the alleles. Most of these involved homonucleotide runs. We observed similar mutations among the three species studied here at, for example, positions 134, 601 , and 612. Kreitman reported, as we do, that introns diverge more rapidly than exons and that flanking DNA diverges more slowly than introns. Langley et al. (1982) and Kreitman both reported that DNA flanking the Adh gene is as highly conserved as that of the structural gene itself, and concluded that large regions of the genome near the Adh gene may be under selective constraints. Comparison of our data with those of Zwiebel et al. (1982) reveals that the entire single-copy component of the genome diverges only slightly faster than does the Adh structural gene, but more than four times more slowly than do the introns. Taken together, these data suggest that much of the DNA of the Drosophila genome may be under sequence-specific selection pressure. Grula et al. (1982), using a very different approach, compared two sea urchin genomes and came to a similar conclusion.

The phylogenetic relationships shown in Fig. 3 have been established on the basis of several criteria, including the pattern of polytene chromosome inversions; protein allelomorphs; interspecies sterilities; mating songs; and molecular similarity in heatshock genes, mitochondrial DNA, ribosomal RNA, serum proteins, and histone genes (reviewed by
Table 3. Estimated divergence times of three drosophilids based on sequence divergence of the Adh gene

\begin{tabular}{lll}
\hline & $\begin{array}{l}\text { Divergence } \\
\text { of Adh } \\
\text { gene }(\%)^{\mathbf{a}}\end{array}$ & $\begin{array}{l}\text { Estimated } \\
\text { dime of } \\
\text { divergence } \\
\text { (millions of } \\
\text { years ago) }\end{array}$ \\
\hline D. simulans/D. melanogaster & 2.8 & 4.2 \\
D. simulans $D$. mauritiana & 1.8 & 2.7 \\
D. mauritiana/D. melanogaster & 3.1 & 4.7 \\
\hline
\end{tabular}

a Total divergence including exons, introns, and 127 nucleotides $5^{\prime}$ to the gene; from Table 1

${ }^{b}$ Obtained by division of the percentage divergence of the Adh gene by the minimum rate of divergence of total single-copy DNA in drosophilids $(0.66 \%$ per million years) calculated by Zwiebel et al. (1982). These are maximal estimates as described in the text

Dover et al. 1982). Conclusions from DNA sequence comparisons of the Adh gene reported here are entirely consistent with those of these other studies. This fact is interesting not in that it corroborates previous measurements, but rather because it supports the idea that in at least some cases reliable phylogenies can be constructed on the basis of the DNA sequence of a single gene.

Although the phylogeny of Fig. 3 is well established, it is much more difficult to determine the times at which the species diverged. In a previous study we measured the extent of divergence of total single-copy DNA in a number of drosophilids using DNA hybridization and thermal elution from hydroxylapatite (Zwiebel et al. 1982). Based on the single-copy divergence rate and on divergence times estimated from several unrelated criteria, we estimated the nucleotide substitution rate of drosophilids to be at least $0.66 \%$ of bases per million years. This rate can be applied to the extent of divergence of the Adh gene reported here to yield an estimate of the divergence times of these species. Dividing the degree of divergence of the Adh gene by the rate of nucleotide substitution yields estimates of 4.2 , 2.7, and 4.7 million years since the separations of $D$. simulans/D. melanogaster, $D$. simulans $/ D$. mauritiana, and $D$. mauritiana/D. melanogaster, respectively (Table 3 ). Since the nucleotide substitution estimate is a minimal approximation, these times probably represent a maximal estimate.

These estimates of divergence time are highly speculative and based on at least two assumptions. The first is that the Adh gene is diverging at approximately the same rate as total single-copy DNA. This appears to be the case, because the extent of single-copy divergence of $D$. melanogaster with respect to $D$. simulans or $D$. mauritiana was measured to be about $2.2 \%$ (Zwiebel et al. 1982), which is similar to the overall degree of divergence of the 
Adh gene (Table 3). The second assumption is that single-copy DNA divergence of drosophilids is approximately linear with time. Additional research will be required to test the validity of this concept.

Acknowledgments. We thank D. Goldberg for providing us with the $D$. melanogaster Adh clone, M. Meselson for genomic clone libraries, and $\mathrm{C}$. Benyajati for providing the sequence of portions of the $D$. melanogaster Adh gene before publication. We acknowledge the assistance of $\mathrm{M}$. Lomax in DNA sequencing. This work was supported by NIH Training Grant GM-07315 to V.H.C. and NIH Grant GM-28851 to G.P.M.

\section{References}

Benton WD, Davis RW (1977) Screening $\lambda$ recombinant clones by hybridization to single plaques in situ. Science 196:180182

Benyajati C, Wang N, Reddy A, Weinberg E, Sofer W (1980) Alcohol dehydrogenase in Drosophila: isolation and characterization of messenger RNA and cDNA clone. Nucleic Acids Res 8:5649-5665

Benyajati C, Place AR, Powers DA, Sofer W (1981) Alcohol dehydrogenase gene of Drosophila melanogaster: Relationship of intervening sequences to functional domains in the protein. Proc Natl Acad Sci USA 78:2717-2721

Benyajati C, Spoerel N, Haymerle H, Ashburner M (1983) The messenger RNA for alcohol dehydrogenase in Drosophila melanogaster differs in its $5^{\prime}$ end in different developmental stages. Cell 33:125-133

Blattner FR, Williams BG, Blechl AE, Denniston-Thompson K, Faber HE, Furlong LA, Grunwald DJ, Keifer DO, Moore DD, Schumm JW, Sheldon EL, Smithies O (1977) Charon phages: safer derivatives of bacteriophage lambda for DNA cloning. Science 196:161-169

Breathnach R, Chambon PA (1981) Organization and expression of eucaryotic split genes coding for proteins. Annu Rev Biochem 50:349-383

Brown WM, Prager EM, Wang A, Wilson AC (1982) Mitochondrial DNA sequences of primates: tempo and mode of evolution. J Mol Evol 18:225-239

Cann RL, Wilson AC (1983) Length mutations in human mitochondrial DNA. Genetics 104:699-711

Craik CS, Sprang S, Fletterick R, Rutter W (1982) Intron-exon splice junctions map at protein surfaces. Nature 299:180-182

Dover G, Brown S, Coen E, Dallas J, Strachan T, Trick M (1982)
In: Dover GA, Flavel RB (eds) Genome evolution. Academic Press, London, pp 343-374

Gilbert W (1978) Why genes in pieces? Nature 271:501

Go M (1981) Correlation of DNA exonic regions with protein structural units in hemoglobin. Nature 291:90-93

Goldberg DA (1980) Isolation and partial characterization of the Drosophila alcohol dehydrogenase gene. Proc Natl Acad Sci USA 77:5794-5798

Goldberg M (1979) Ph.D. Thesis, Stanford University, Palo Alto, California

Grula JW, Hall TJ, Hunt JA, Giugni TD, Graham GJ, Davidson EH, Britten RJ (1982) Sea urchin DNA variation and reduced interspecies differences of the less variable DNA sequences. Evolution 36:665-676

Kreitman M (1983) Nucleotide polymorphism at the alcohol dehydrogenase locus of Drosophila melanogaster. Nature 304 : 412-417

Langley CH, Montgomery E, Quattlebaum WF (1982) Restriction map variation in the Adh region of Drosophila. Proc Natl Acad Sci USA 79:5631-5635

Maxam A, Gilbert W (1977) A new method for sequencing DNA. Proc Natl Acad Sci USA 74:560-564

Moore GP (1983) Slipped-mispairing and the evolution of introns. Trends Biochem Sci 8:4!1-414

O'Donnell J, Gerace L, Leister F, Sofer W (1978) Chemical selection of mutants that affect alcohol dehydrogenase in Drosophila. Genetics 79:73-83

Perler F, Efstratiadis A, Lomedico P, Gilbert W, Kolodner R, Dodgson J (1980) The evolution of genes: the chicken preproinsulin gene. Cell 20:555-566

Sofer W, Ursprung H (1968) Drosophila alcohol dehydrogenase J Biol Chem 243:3110-3115

Spradling AC, Rubin GM (1981) Drosophila genome organization: conserved and dynamic aspects. Annu Rev Genet 15 : 219-264

Thatcher DR (1980) The complete amino acid sequence of three alcohol dehydrogenase alleloenzymes from Drosophila melanogaster. Biochem J 187:875-886

Ursprung H, Sofer W, Burroughs N (1970) Ontogeny and tissue distribution of alcohol dehydrogenase in Drosophila melanogaster. Wilhelm Roux Arch 164:201-208

Woodruff RC, Ashburner M (1979) The genetics of a small autosomal region of $D$. melanogaster containing the structural gene for alcohol dehydrogenase. Genetics 92:117-132

Zwiebel LJ, Cohn VH, Wright DR, Moore GP (1982) Evolution of single-copy DNA and the ADH gene in seven drosophilids. J Mol Evol 19:62-71

Received January 13, 1983/Revised November 24, 1983 